apply. Would Dr. Alexander keep a patient for "2-3 min" without oxygen enrichment after an adequate dose of suxamethonium? Even the "vigorous" method of ventilation, on his figures, seems inefficient.-I am, etc.,

London W.1

M. W. P. HUDSON

\section{Cerebral Vasodilators}

SIR,-Like the British National Formulary 1974-76, the excellent anticle on the treatment of organic brain syndromes by Dr. R. A. Wood (29 March, p. 723) makes no mention of the so-called cerebral vasodilators. These are widely advertised and prescribed but they are expensive and, once their exhibition is begun, there is seldom any reason why this should not be continued indefinitely (however bad things may be, one can always think they might otherwise be worse). The drugs must cost the country a fortune. May we assume that Dr. Wood thinks they are no good? -I am, etc.,

Glasgow

H. G. EASTON

${ }_{*}^{*}$ We showed Dr. Easton's letter to Dr. Wood, whose answer is printed below.-ED., B.M.f.

SIR,-The two most widely used cerebral vasodilators, cyclospasmol and hydergine, have been available for many years and have been generally regarded as ineffective, though oocasionally benefit appears to have been shown in the controlled trial setting. There is little current support for cyclo spasmol, a vasodilator pharmacologically similar to papaverine. Hydergine is more fashionable and is an ergot derivative which antagonizes alpha-adrenergic cerebral vasoconstriction but lacks the direct vasoconstrictor effect which makes many ergot alkaloids unsuitable for long-term use.

It could be argued that hypoxia alneady represented a maximal vasodilator stimulus on diseased vessels themselves incapable of dilatation. However, a redistributive effect cannot be ruled out, as with nitrites in the ischaemic myocardium. Because of the probability that primary neuronal dementia is not a vascular disease and because vasodilatation seems so unlikely in cerebrovascular disease the drugs are also talked of as "cerebral activators."

I am one of a majority, including Dr. H. M. Hodkinson (5 April, p. 23), who do not accept the evidence for the use of these drugs. Despite the telling fact that they have not caught on in an age when many placebo remedies have, it is still not possible to say conclusively that they are useless so long as some properly conducted trials point to benefit.-I am, etc.,

Perth

ROBERT A. WOOD

\section{Poisoned Children}

SIR,-We would like to reply to the comments by Mr. M. W. Calnan and Dr. J. W. Dale and by Mr. C. P. de Fonseka ( 1 March, pp. 511-512) on our letters (26 October 1974, p. 231 and 11 January, p. 95) regarding the problems of accidental poisoning in ahildren. We agree that a separation into true poisoning and poisoning scares is important from an epidemiological and prevention campaign point of view, but for the practical management of children suspected of being poisoned it is of less value. Questions should be asked of the parents in terms of the possible substance ingested. If this proves to be a substance which is known to be non-toxic-for example, one of the penicillins or oral contraceptives-then no further treatment is required except that of advice to the parent to keep all medioines out of reach of children. However, if the substance is potentially toxic then full evaluation of the patient, with adequate treatment and observation, is necessary. Aspirin is the commonest substance with which children are poisoned, and some reduction of the numbers of children admitted following such episodes could be achieved by following the nomogram published by Done, ${ }^{1}$ in which fairly accurate assessment of the likely severity of the poisoning episode can be obtained by measuring the blood salicylate level six hours after ingestion. There are very few other commonly ingested substances which can be easily measured, but iron and digoxin estimations may prove useful and may be available in the larger centres.

The suggestion that an 18-month-old child lefit alone with a bottle of aspirin for only one minute could have ingested only one tablet at the most indicates a lack of understanding of the abilities of some children of this age and indeed indicates why mothers may on occasion underestimate the severity of the problem.

We maintain that any campaign of health education should be directed to prevention of the poisoning episode and not to the dangerous suggestion of asking parents not to bother the primary care services with what the parents consider to be a seriou situation. We agree that education of the primary care physician or accident room house officer to differentiate between toxic and non-toxic substances should be encouraged, but to suggest differentiation between true, possible, and unlikely poisoning with a potentially lethal substance is to court disaster.

In our view an important aspect of health education is that part of it must be directed not to the public at large but to "the powers that be." We entirely agree with Dr. Dale and Mr. Calnan when they say that parents should be provided with preventive measure which have been shown to be effective through experimental and field studies. Lack of initiative and drive at Government and Departmental level is the main reason why such measures (whether child-resistant containers or strip packaging) have not so fa been introduced, and health education directed at those responsible for this would pay handsome dividends if it was successful in effecting the introduction of childresistant containers etc.-We are, etc.

A. W. CRAFt

Department of Child Health, University of Newcastle, Newcastle upon Tyne

R. H. JACKSON

University Hospital of Wales,

Cardiff

J. R. SibERT Providence Hospital

1 Garrod, L. P., Lambert, H. P., and O'Grady, F., Antibiotic and Chemotherapy, p. 243. London, Antibiotic and Chemotherapy,
SIR,-I should like to offer some thoughts in response to the letter from Miss Margaret Witt ( 1 March, p. 514).

While the Horizon programme on the nduction of labour was biased, I believe it was rightly so. For it demonstrated clearly hat inductions have been performed when they were not necessary and to the detrimother and child. Such a position every right to challenge it. That other dethers at term that anduction would be

"consumer" may also detreatments-for example, "the happiA responsible profession must reand to demands from within and without mot attempt to constrain the popular comings. - I am, etc.,

Michael HaRT

Wospital,

\section{Treatment of Eye Injuries}

SIR,-In their description of the treatment of casualties arising out of the recent bomb explosions in Birmingham (5 April, p. 25) 17) who sustained bilateral corneal abrasions was treated with amethocaine and sulphatamide drops.

Sulphonamides exert their action by com petitive inhibition of the enzyme tetraacid, a folic acid precursor, from paraaminobenzoic acid and 2-amino-4-hydroxytetrahydropteridine. This action is the result of the similarity of the structure of paraminobenzoic acid and sulphonamide. is a derivative of pana fere with the action of the sulphonamides. andically inactive combination. (cases 10 and 14) were treated ith chloramphenicol drops without the use reasons foraine, with no comment on the some cases and sulphacetamide in others.

I have found that amethocaine is unsatisfactory for routine use in casualty work, come few minutes when its local this reason I no longer use amethocaine but is oxybuprocaine, which is free of this inritant effect. Of course, oxybuprocaine and sulphacetamide cannot be used together. Final-year Medical Student Carr mention that one of their parients

R. A. Evans 